\title{
Development and Implementation of Training Actions in Health Services
}

\author{
Georgios Panagiotopoulos \\ University of Patras \\ Megalou Alexandrou 1, Patras, 26334, Greece \\ Tel: 69-72-663-858 E-mail: pangiorgos@upatras.gr \\ Georgaki Theodora \\ Hellenic Open University \\ Tel: 69-32-598-247Ｅ-mail: dorageorgaki@gmail.com \\ Zoe Karanikola (Corresponding Author) \\ University of Patras \\ Megalou Alexandrou 1, Patras, 26334, Greece \\ Tel: 69-49-973-053Ｅ-mail: zoekaranikola3@gmail.com
}

Received: August 23, 2019 Accepted: September 25, 2019 Published: September 30, 2019

doi:10.5296/ijld.v9i3.15553 URL: https://doi.org/10.5296/ijld.v9i3. 15553

\begin{abstract}
The purpose of this study is to investigate the way the Hippocrates Hospital staff is trained, the principles of learning implemented in the programs of the particular hospital unit, and the impact of the training on the participants themselves. The quantitative methodology was chosen for the collection of data, whereas the population - sample consists of 70 doctors and nurses participating in hospital training programs either as trainers or as trainees. According to the research findings, trainers take into account the needs and interests of trainees and feel capable of educating them. The question-answer technique is mainly used, while the lecture technique is less used. After having completed the training programs, participants state that they feel more confident, they recognize the value of education and training, support lifelong learning and express great interest in participating in new training programs.
\end{abstract}


Keywords: training, learning principles, learning techniques, healthcare staff, trainers, trainees

\section{Introduction}

The process of training seems to be an urgent need especially in the 21 st century, as we are at the beginning of the fourth technological revolution, which undoubtedly affects all areas of human living, bringing about rapid changes in lifestyle, work, communication and interaction. Employees are required to redefine their work profile with appropriate and right skills (Karanikola \& Panagiotopoulos, 2019).

In-service training is a key strategic approach to addressing the severe shortage of healthcare workers in many countries and reducing medical errors. In the USA, a project regarding training evaluation has been developed. This evaluation focuses on the outcomes of such programs and the development of potential better practices that respond more effectively to learners' needs, whereas the practical constraints on resources, timetables and complexity of international health service systems are recognized at the same time (Malley et al., 2013).

In Greece, the Law 2889/2001 allows each hospital to establish an independent Education Office, which is under the supervision of the Hospital Administrator. Hospitals with a dynamic capacity of more than 400 beds are allowed to set up separate departments of Quality Control, Research and Continuing Education. The Hospital Continuing Education Office undertakes the development of training programs for the Hospital staff, having first focused on identifying staffing needs. As part of their efforts to train the staff, the hospital units have set up continuing education offices, such as the Nursing Service, which organizes training programs.

Given that medical education continues its dynamic transformation (Reed et al., 2014), the present research is expected to fill the cognitive gap that exists, especially with regard to the way doctors and nurses, who have not acquired pedagogical training during their basic studies, can organize and implement training programs.

\subsection{Theoretical Underpinning}

\subsubsection{Health Education Programs}

Training programs organized for healthcare may be financed by the Ministry of Health, hospitals, insurance funds, pharmaceutical industries, whereas they can take place in classrooms, laboratories and workplaces. When the fastest possible learning is particularly sought after, in-service training is considered to be the right type of education (Day, 2003).

This is also confirmed by a research conducted by the Health Foundation (2012), which refers to a training program regarding the safety in a Canadian hospital unit. Similarly in the USA, in a two-year training program attended by health officials of a whole county (about 600 people), participants found that their improvement was significant in the areas they were trained. In addition, the basic training that a health professional (mainly a nurse) receives is impaired after five years. Some even argue that the shortage of the right training also leads to poor quality of service delivery (Gillies \& Petengill, 1993).

The participation of health care providers in training programs has not yet reached the desired 
level, given that most European countries have not still developed a common line of training, while health workers appear to be particularly discouraged when there is no in-service training program in the workplace (Kalita et al., 2009). In a survey (Pierrakos et al., 2006) of 632 health care providers (doctors and nurses), $31 \%$ of doctors and $48.1 \%$ of nurses stated that they have never participated in training programs mainly because of their professional obligations. Similarly, $19.7 \%$ of doctors indicate that they do not participate in training programs due to lack of interest in additional knowledge.

The Ministry of Health of Greece, in cooperation with the European Union, organizes various programs for health education recognizing their right and the need for continuous education. The ultimate goal is to improve the services provided, either by attending training group sessions, practice sessions or through personalized training (Health Foundation, 2012).

At this point it is worth noting that over the last years training of public servants in general is compulsory, irrespective of employees' working area and level (Kelesi \& Stavropoulou, 2010), whereas the Ministry of Health has set targets for intervention in health services for the period 2017-2020. Though much of the current legislation is not implemented (Tzortzopoulos, 2017).

\subsubsection{Training Methods}

Most of the 5,000 articles written on health education programs and efforts to improve the services provided do not describe the methods used and their effectiveness (Health Foundation, 2012). In some cases, though, there are references only on utilizing practical exercises and activities.

According to Hatzipanayiotou (2001), the most popular method of staff training is the seminar, through which trainees can acquire more knowledge and skills in order to improve the quality of their services. In addition, there is a variety of other methods and techniques used on a case-by-case basis. Examples include technology-based learning, simulators, on-the-job training, coaching, lectures, group discussions, role playing, management games, outdoor education, film and video, case study, scheduled reading, standardized patients, clinical teaching, symposium, one-on-one education, feedback.

In addition, a widely used method is problem solving, which was first applied to doctors' training programs at McMaster University in the mid-1960s (Solomon, 2005) and ever since it has been used in many health education programs (Neville, 2009). In addition, seminars were held in a hospital in England in order to develop critical thinking and nursing skills, while in a hospital in America the method of feedback was used. In particular, 102 mental health professionals videotaped their sessions and then they got a review. Also in forty-five Australian hospitals, clinicians, who participated and realized that they were lagging behind their colleagues, were motivated to begin the process of development and improvement (Health Foundation, 2012).

\subsubsection{The Role of the Health Trainer}

The role of health educators is increasingly recognized as a professional activity of major importance (Purcell \& Lloyd-Jones, 2003). In the case of physicians, it is assumed that upon 
obtaining their degree, they acquire the ability to teach new medical students or to train health professionals in a field related to their specialty (Cheesman, 2009). In addition, they usually derive from the position of a lecturer, professor or researcher (George et al., 2006) and they are called upon to stimulate the interest of their learners despite the fact that they lack in adult education techniques and theories. This obstacle may be overwhelming by getting assistance from more experienced physicians or even by trainees themselves who can act as co-editors of the programs.

The physicians, as a key principle for fulfilling their role as a trainer successfully, should have proper planning (Spencer, 2003) and the ability to adapt their teaching to the conditions and trainees they encounter. An incentive for quality assurance in their training work is the establishment of an evaluation of these programs. Evaluation examines the program's planning and purpose, the learning methodology chosen to achieve the goals, and the educational material used by the trainer (George et al., 2006).

Concerning nurse trainers, few studies have been published (González \& Font, 2012). The trainers take on the role of trainer without any relevant training and apply strategies driven by their personal perceptions as well as the learner's profile. Research done by hospital nurses in Attica (Kavga et al., 2016) shows that $45.7 \%$ of surveyed nurses would like to learn more about teaching methods, while $26.6 \%$ would like more information on the principles of adult education.

It is therefore worth focusing on the process of shaping the identity of the instructors and the way they choose their educational practices. Thus, a survey of 132 physicians and dental educators (Mohanna et al., 2007) found different types of educators. Particularly, a flexible and adaptive teacher makes effective use of many different teaching activities, teaches comfortably and is fully aware of how the environment affects both the trainer and the trainees. The sensitive one focuses on the learner, prefers teaching in small groups, is highly emotional, uses role playing and avoids straight presentations. The typical teacher is strictly prepared, accredited and fully aware of his or her task, while the direct type focuses on specific skills and prefers not to engage in multidisciplinary teaching and learning. In addition, there is the type who prefers to teach in front of a large audience, and also the one who wishes to teach small classes of self-taught subjects, often "ad hoc", without help and without continuity.

\section{Methodology of Research}

\subsection{Research Objective - Research Tool}

This study comes to investigate the training programs held in a particular hospital and the principles of learning applied. The following research questions are explored to achieve this end:

- To what extent are those involved in a training seminar aware of basic terms of adult education?

- To what extent do trainers focus on the experiences of their trainees in order to choose their teaching methods and the content of the programs? 
- To what extent do trainees get more knowledge after attending a training program?

- To what extent is the personality of the trainees affected?

The sample consisted of 70 physicians and nurses of the Hippocrates Hospital of Thessaloniki, while the sampling strategy was probability sampling, which is considered the most stringent form (Cresswell \& Clark, 2010). Specifically, a random sample of representative sample was used.

The data collection was based on a four-part questionnaire. The first part included closed-ended questions regarding the demographic information of the trainer or the trainee (questions 1-7). In the second part (questions 8-9) the participants reported the degree of their involvement in the planning of training seminars and the degree of using techniques consistent with the principles of adult education. In the third part (questions 10-11) they mentioned the role of the trainer and his/her degree of freedom in organizing training seminars and finally part four (question 12) reported the effects of training from the perspective of trainers and trainees.

The questionnaires were processed by using the Statistical Package for Social Sciences, SPSS V.25 where the variables were defined. Initially, a pilot study was carried out, followed by test-retest reliability. As far as the reliability of the scale, the Cronbach's Alpha, the statistical index of internal consistency, as a whole was 0.7 , which represents satisfactory quality of the measurement.

\subsection{Quantitative Research Results: Univariate Analysis}

39 out of the 70 participants were physicians (55.7\%) and 31 (44.3\%) nurses. The majority of respondents were women ( $71.4 \%$ vs. $28.6 \%$ for men), whereas regarding the position of participation in the training programs, the majority participated as trainees (58.6\%). Regarding the age, the majority (37.1\%) were 51-60 years old. This group is followed by the ages of 41-50 years $(22.9 \%), 23-30$ years $(17.1 \%), 61$ years and over $(12.9 \%)$ and $31-40$ years $(10 \%)$.

In terms of studies, most of the participants (44.3\%) had a degree, slightly fewer (41.4\%) had a master's degree, $12.9 \%$ had a doctorate, while $1.4 \%$ had a second degree only. In terms of their professional experience, most (31.4\%) are employees over 26 years, followed by those with 16-25 years of service (28.6\%). Regarding their marital status, a very large proportion of the participants $(65.7 \%)$ were married, whereas $25.7 \%$ were unmarried and $4.3 \%$ widowed or divorced.

On the question whether the training programs of this hospital take into account the needs of the trainees, the average score was 3,54 points (standard deviation 1,236). On the question whether the interests of the trainees were taken into account, the mean score was 3,29 (standard deviation of 1,342), while on the question of whether the participants were enthusiastic, the mean score was 2,14 (standard deviation of 1,195). Finally, on the question of how much the trainees feel that training in not a waste of time, the mean score was $3,21(1,178)$ while on the question of whether the trainees feel that their participation affects their image, the mean score was 3,76 (standard deviation 1,209).

Regarding the degree of utilization of adult education techniques used in Hippocrates training 
programs, the question-answer method seems to be more applicable, with a mean of 4,14 (standard deviation ,767). Lecture follows with a mean of 4,06 (1,048 standard deviation), and then discussion with 4,03 average (1,063 standard deviation), demonstration with 3,91 (standard deviation of 1,248), the study visit with an average of 3,63 (standard deviation 1,342), exercises, workgroups and simulation with a mean of 3,37 each (standard deviation 1,553), interview with a specialist with a mean of 3,21 (standard deviation 1,483) and role play with a mean of 2,79 (standard deviation 1,587). Research has shown that the brainstorming technique with an average value of 2,77 (standard deviation 1,342) is the less used. Concerning the role that the trainer should play, the following results emerged:

Table 1. Instructors should adapt their material to the needs of the trainees.

\begin{tabular}{lllcc}
\hline & Frequency & $\%$ & Existing percentage & Cumulative percentage \\
\hline No & 6 & 8,6 & 8,6 & 8,6 \\
Yes & $\mathbf{6 4}$ & $\mathbf{9 1 , 4}$ & 91,4 & 100,0 \\
Total & 70 & 100,0 & 100,0 & \\
\hline
\end{tabular}

Table 2. The instructor needs to know the meaning of learning and the purpose of adult education.

\begin{tabular}{ccccc}
\hline & Frequency & $\%$ & Existing percentage & Cumulative percentage \\
\hline No & 19 & 27,1 & 27,1 & 27,1 \\
Yes & $\mathbf{5 1}$ & $\mathbf{7 2 , 9}$ & 72,9 & 100,0 \\
Total & 70 & 100,0 & 100,0 & \\
\hline
\end{tabular}

Table 3. The trainer should develop educational skills

\begin{tabular}{lllcc}
\hline & Frequency & $\%$ & Existing percentage & Cumulative percentage \\
\hline No & 5 & 7,1 & 7,1 & 7,1 \\
Yes & $\mathbf{6 5}$ & $\mathbf{9 2 , 9}$ & 92,9 & 100,0 \\
Total & 70 & 100,0 & 100,0 & \\
\hline
\end{tabular}

Table 4. The trainer should be confident.

\begin{tabular}{lllll}
\hline & Frequency & $\%$ & Existing percentage & Cumulative percentage \\
\hline No & 3 & 4,3 & 4,3 & 4,3 \\
Yes & $\mathbf{6 7}$ & $\mathbf{9 5 , 7}$ & 95,7 & 100,0 \\
Total & 70 & 100,0 & 100,0 & \\
\hline
\end{tabular}


As far as the degree of the respondents' consent regarding what the trainer could do during the training programs, most respondents stated that the trainer could choose his/her material with an average of 4,33 (standard deviation ,675). The view that the trainer could assign appropriate tasks to the trainees, with an average of 4,30 (standard deviation, 622) and the perception that the trainer could divide the material based on what might be effective in practice, with a mean of 4,14 (standard deviation ,748) follow.

Regarding the results of the training programs, most trainees with a mean of 4,03 (standard deviation , 978) responded that after completing a training program they feel more confident, more interested in participating in new programs (mean 4,00 and standard deviation ,978) and willing to extend it (mean 3,76, standard deviation 1,069).

\subsection{Quantitative Research Results: Bivariate Analysis}

Non-parametric Mann-Whitney $U$ rank test was used to investigate the relationship between a binary nominal variable and a dependent regular variable, while the Wall-rank Kruskal parameter check was applied to investigate the relationship between a multivariate nominal variable and an independent regular variable. The level of statistical significance in all cases was set at $0.05(\mathrm{p}<0.05)$.

The non-parametric Mann-Whitney U test, with independent samples of physicians and nurses, showed that the attitudes of physicians and nurses seemed to contradict the extent to which their trainees' interests were taken into account by the trainers. Doctors argue to a greater extent than nurses that this principle appears to have been applied in the training programs they have attended $(\mathrm{p}$-value $=0.012<0.05)$.

In addition, non-parametric Mann-Whitney $U$ test, with independent samples of women and men, showed that gender significantly differentiated participants' views on the extent to which educational principles are applied in training programs, with men believing more than the women that the interests of the trainees are taken into account ( $p$-value $=0.036<0.05$ ).

In addition, the non-parametric Mann-Whitney $U$ test, with independent samples of trainers and trainees, showed that respondents' position of participation varied statistically significantly in their views on the extent to which educational principles were applied in training programs. Specifically, trainers believe, more than trainees, that the needs of trainees are taken into account ( $p$-value $=0.046<0.05$ ), that trainees participate in the organization of the training program $(\mathrm{p}$-value $=0.001<0.05)$ and that trainees feel they are not wasting their time $(\mathrm{p}$-value $=0.010<0.05)$.

In addition, the non-parametric Kruskal-Wallis test, with independent samples of age groups, showed that the age of the participants varied statistically significantly with regard to the extent to which educational principles are applied in training programs (question 8) with age group of 41-50 years to believe to a lesser extent than others, that trainees' needs are taken into account $(\mathrm{p}$-value $=0.025<0.05)$ and that trainees' interests are taken into account $(\mathrm{p}$-value $=0.016<$ $0.05)$.

Regarding years of service, there is still a statistically significant difference, with respondents 
with 1-5 years of service feeling less that trainees' needs are taken into account ( $\mathrm{p}$-value $=$ $0.016<0.05$ ). In addition, respondents with $6-15$ years of service experience believe less that trainees are not wasting their time $(\mathrm{p}$-value $=0.009<0.05)$.

Respondents' position (trainer or trainee) in programs significantly differentiates their responses to the extent to which teaching techniques are used, with trainees perceiving that simulation technique is used more frequently ( $\mathrm{p}$-value $=0.003<0.05$ ).

The job position also significantly differentiates respondents' views on the extent to which training techniques are used in training programs, with nurses experiencing more frequently than physicians the question-and-answer techniques ( $\mathrm{p}$-value $=0.049<0.05$ ), exercises $(\mathrm{p}$-value $=0.005<0.05)$, workgroups $(\mathrm{p}$-value $=0.005<0.05)$, simulation $(\mathrm{p}$-value $=0.031$ $<0.05)$ ), demonstration ( $\mathrm{p}$-value $=0.021<0.05$ ), educational visit ( $\mathrm{p}$-value $=0.039<0.05$ ), and expert interviewing $(\mathrm{p}$-value $=0.006<0.05)$. In addition, widows and divorced persons have experienced the simulation technique $(\mathrm{p}$-value $=0.021<0.05)$ more frequently than married couples and bachelors.

The age of the participants significantly differentiates the respondents' viewpoints on the extent to which training techniques are utilized in training programs, with respondents aged 31-40 having little experience of role-playing technique ( $\mathrm{p}$-value $=0.008<0.05$ ).

Participants' years of service differs statistically in terms of the extent to which training techniques are used in training programs, with 1-5 years of service respondents having little or no discussion with others ( $\mathrm{p}$-value $=0.047<0.05$ ) and exercises ( $\mathrm{p}$-value $=0.027<0.05$ ). In addition, respondents with 16-25 years of service experience to a lesser degree, than others, the use of case study techniques ( $p$-value $=0.009<0.05)$ and workgroups $(p$-value $=0.024<0.05)$.

According to the results of the non-parametric Mann-Whitney U ranking test, respondents' participation in training programs did not significantly differentiate their responses regarding the role of the program trainer. The job position of the respondents in the training programs differentiates statistically significantly the answers of the research participants regarding the role that the trainer should have, with the physicians to believe to a greater extent than the nurses, that the instructor must adapt his/her material to the needs of the trainees ( $p$-value $=$ $0.046<0.05)$.

Unmarried people and widows believe to a greater extent that the trainer needs to know the meaning of learning and the goals of adult learning ( $p$-value $=0.022<0.05$ ). In addition, the widows believe to a lesser degree that the instructor has to adapt his/her material to the needs of the trainees ( $\mathrm{p}$-value $=0.001<0.05)$.

In addition, 23-30 year old believed to a lesser degree that the trainer could choose his/her teaching material ( $\mathrm{p}$-value $=0.011<0.05$ ), as well as that the trainer was able to assign appropriate tasks to the trainees of the training program $(\mathrm{p}$-value $=0.020<0.05)$.

The marital status of the participants affects significantly their views on the extent to which the actions taken after the completion of the training program have been implemented, with the divorced to believe that the trainees continue to study on their own after completing their 
training programs $(\mathrm{p}$-value $=0.014<0.05)$.

The job position also affects statistically significantly the participants' viewpoints on the results obtained after completion of the training programs. Nurses believe, to a greater extent, than physicians, that abandoning the training programs is increasingly less likely to happen ( $\mathrm{p}$-value $=0.005<0.05$ ). As for the rest of the results after the completion of the training programs, their average rankings for both doctors and nurses are not significantly different.

\section{Discussion on the Results}

The statistical analysis of the present study initially shows that the job, gender, place of employment, marital status, age and years of service significantly influence the answers of trainers and trainees regarding the training principles and techniques and the characteristics that a trainer has or should have.

Regarding the knowledge of basic terms of adult education, it appears that the respondents were aware of these terms. In fact, this research has shown that trainees understand that the question-and-answer technique is more practiced in this hospital than all other techniques. This finding is opposed to previous studies according to which lecture is the most frequent technique (Koutsourelakis, 2015).

Concerning the role of trainer, trainers and trainees argue that he/she should take into account the needs of the trainees and develop the right instructional skills (Reed et al., 2018). Supporters of this view are mostly doctors. The most tolerant towards instructor's weaknesses appear to be the unmarried and the widows, who argue that the instructor must know primarily what learning means and what the purpose of adult education is. Finally, to a greater extent, they believe that in order to achieve their goal, the trainer must be confident.

The research also revealed that those who participated in hospital training programs noticed that their trainer had the ability to choose his/her material, utilize the principle of active participation (Panagiotidou \& Zissi, 2013), assign appropriate tasks to participants and distribute his/her material based on what is considered effective. The stricter judges of the trainers were the younger ones (23-30) and the less experienced, who believed that their trainer could not choose to a great extent his/her material and assign appropriate tasks to his trainees. As it has also been shown by research in St. Lucia (Gaspard \& Che-Ming, 2016), the younger ones have higher expectations.

Of particular interest is the fact that those who participated in Hippocrates' in-hospital training programs do not share the same view of how trainees are treated. For example, physicians who participated in training programs refute what emerged from other researches on teacher training (Koutsourelakis, 2015; Frangoulis \& Christopoulos, 2014). Doctors, in contrast to nurses, believe that instructors were taking into account the interests of the trainees. Men have the same perception. Trainers, in contrast to trainees, also consider the needs of trainees, who appear to be actively involved in the organization of the programs, and apparently the trainees feel that they are not wasting their time. It is also worth noting that the participation of trainees in the organization of training programs remains a requirement for some participants. On the other hand, the depreciation of the trainees is observed by the middle-aged participants (41-50 
years) and those who have little experience.

Concerning the degree to which the participants in the training programs were pushed to further knowledge, almost all equally stated that these programs offered them new knowledge (Ohnishi, 2007) and motives to continue. Consequently, they seem to understand the value of the knowledge they acquire, as previous research has shown (Pierrakos et al., 2016) and finally, they realize that this is a way to get away from the daily routine.

This research has shown that in some cases the needs and interests of trainees seem to be disregarded. It is therefore worth investigating the reasons why this happens. In addition, it was observed that middle-aged participants (ages 41-50) appeared to be more satisfied than younger and those with a lower service life. It is therefore necessary to look for the factors that lead to the different degree of satisfaction. In addition, it might be worth exploring which technique is more satisfying for a trainee in order to be more utilized in the future.

Finally, the Cronbach's Alpha for the scale as a whole was satisfactory. However, this particular scale has never been used before. Consequently, it is suggested that it should be tested in many other similar cases. In addition a qualitative research can complement and enrich this quantitative approach, as the comparison of the two seems to create new academic interest and implications.

\section{References}

Bizas, L. (2011). Certification and Recognition of Continuing Nursing Education. Greek Journal of Nursing Science, 4(1).

Cheesman, N. (2009). Doctors as teachers. BMJ, 338. https://doi.org/10.1136/bmj.b1551.

Christodoulou, E. (2017). New Technologies in Nursing Education. Greek Journal of Nursing Science, 10(1), 3-5.

Creswell, J. W., \& Plano Clark, V. L. (2010). Designing and Conducting Mixed Methods Research. London: SAGE Publications, Inc.

Day, C. (2003). The Evolution of Teachers. The Challenges of Lifelong Learning. Athens: Dardanos.

Frangoulis, I., \& Christopoulos, K. (2014). Investigating the Views of Physical Education Teachers Regarding the Utilization of Adult Methodology in their Participation in Training Programs. Educational Cycle, 2.

Gaspard, J., \& Che-Ming, Y. (2016). Training Needs Assessment of Health Care Professionals in a Developing Country: The Example of Saint Lucia. BMC Medical Education, 16(1). https://doi.org/10.1186/s12909-016-0638-9

George, C., Nathanson, V., \& Seddon, C. (2006). Doctors as Teachers. BMA Board of Science.

Gillies, D., \& Petengill, M. (1993). Retention of Continuing Education Participants. Journal of Continuing Education in Nursing, 24, 17-22. 
González, M. A., \& Font, C. M. (2012). The nurse teacher. Construction of a new professional identity. Investigación y Educación en Enfermería.

Hatzipanayiotou, P. (2001). Teacher Training: Issues of Organization, Design and Evaluation. Athens: Dardanos.

Health Foundation (2012). Evidence scan: Quality improvement training for healthcare professionals. Retrieved from: https://www.health.org.uk > default > files

Kalita, A., Zaidi, S., Prasad, V., \& Raman (2009). Empowering Health Personnel for Decentralized Health Planning in India: The Public Health Resource Network. Human Resources for Health, 7, 57. https://doi.org/10.1186/1478-4491-7-57

Karanikola, Z., \& Panagiotopoulos, G. (2019). 4th industrial revolution: The challenge of changing the skills profile of human resources. In Andreadakis, N., Karanikola, Z., Konsolas, M., Panagiotopoulos, G. (Eds.). Human Resources Management. Training and International Policies (pp. 56-66). Athens: Grigoris.

Kavga, A., Vlachou, E., Kalamikerakis, I., Parissopoulos, S., \& Govina, O. (2016). Recording of Clinical Trainers' Views of the Student Learning Environment at the Hospital. Vima Asklipiou, 15(2). Retrieved from: http://ejournals.teiath.gr/index.php/tovima/index

Kelesi -Stavropoulou, N. M., \& Stavropoulou, K. M. (2010). Human Resources Management in the Health Sector. Vima Asklipiou, 9(3). Retrieved from www.vima-asklipiou.gr

Koutsourelakis, Ch. (2015). The University Training Center of Crete and the Adult Education Authorities in the Second Level Training Programs in Information and Communication Technologies. Retrieved from http://cretaadulteduc.gr

Mohanna, K., Chambers, R., \& Wall, D. (2007). Developing your Teaching Style: Increasing Effectiveness in Healthcare Teaching.Postgrad Med J, 200783145-147. https://doi.org/10.1136/pgmj.2006.054114

Neville, A. J. (2009). Problem-based Learning and Medical Education Forty Years on. Medical Principles and Practice, 19, 1-9. https://doi.org/10.1159/000163038

Ohnishi, M., Nakamura, K., \& Takano, T. (2007). Training of Healthcare Personnel to Improve Performance of Community-based Antenatal Care Program. Advances in Health Sciences Education, 12(2), 147-156. https://doi.org/10.1007/s10459-005-2329-x

Panagiotidou, A., \& Zissi, A. (2015). Applying the Basic Principles of Adult Education and Enhancing Interaction in Teacher Education. Educational Cycle, 3(1).

Pierrakos, G., Sarris, M., Amitsis, G., Kyriopoulos, G., \& Soulis, S. (2006). Training Needs and Continuing Training of Human Resources in the Health Sector. Nursing, 45(4), 543-551.

Purcell, N., \& Lloyd-Jones, G. (2003). Standards for Medical Educators. Medical Education, 200337, 149-154. https://doi.org/10.1046/j.1365-2923.2003.01432.x

Reed, S., Shell, R., Kassis, K., Tartaglia, K., Wallihan, R., Smith, K., Hurtubise, L., ... Mahan, 


\section{Macrothink}

International Journal of Learning and Development

ISSN 2164-4063 2019, Vol. 9, No. 3

J. D. (2014). Applying Adult Learning Practices in Medical Education. Curr Probl Pediatr Adolesc Health Care, 44(6), 170-81. https://doi.org/10.1016/j.cppeds.2014.01.008

Solomon, P. (2005). Problem-based Learning: A Review of Current Issues Relevant to Physiotherapy Education. Physiotherapy Theory \& Practice, 21, 37-49. https://doi.org/10.1080/09593980590911499

Spencer, J. (2003). Learning and Teaching in the Clinical Environment. BMJ 2003, 326, 591-594. https://doi.org/10.1136/bmj.326.7389.591

Tzortzopoulos, A. (2017). Implementation of Principles and Tools of Total Quality Management in the Health Sector - Guarantee for Quality Upgrading of Hospitals and the National Health System. Ancient Greek Medicine, 35(5), 649-664.

\section{Diktyografia}

http://www.ippokratio.gr/?page_id=33298

http://www.sismanoglio.gr

https://webcache.gmc-uk.org/analyticsrep

\section{Copyright Disclaimer}

Copyright for this article is retained by the author(s), with first publication rights granted to the journal.

This is an open-access article distributed under the terms and conditions of the Creative Commons Attribution license (http://creativecommons.org/licenses/by/4.0/). 